\title{
Análise da resistência à compressão de concretos com adição de cinza de aterro sanitário
}

\author{
Analysis of the compressive strength of \\ concrete with addition of ash from land- \\ fill
}

\footnotetext{
${ }^{1}$ Departamento de Engenharia Civil, Universidade do Contestado - UnC, Av. Presidente Nereu Ramos, 1071, Jardim do Moinho, CEP 89300-000, Mafra, Santa Catarina, Brasil.

e-mail: eugraupmann@yahoo.com.br, mariane_arrudamartins@hotmail.com, marcioconsul@hotmail.com, luhcechin@gmail.com
}

\section{RESUMO}

O objetivo desse trabalho é identificar o comportamento de alguns traços de concreto no qual há a substituição parcial da areia natural pela cinza de aterro sanitário. Foram propostos quatro traços, o primeiro com $100 \%$ areia natural, que será usado como traço de referência, o segundo com 5\% de cinza de aterro sanitário, em relação a massa da areia natural, o terceiro com $10 \%$ de cinza, e, o quarto com $15 \%$ de cinza. Os traços dos concretos foram compostos de cimento, areia/cinza, brita e água, e, estes foram ensaiados quanto a sua resistência à compressão. Os resultados mostraram que os traços compostos com cinza apresentaram bom desempenho no que se refere a resistência à compressão. A relevância desse estudo se deve ao fato de que, os aterros sanitários, quando utilizado o processo de queima do lixo, produzem cinzas, ocasionando um impacto na natureza que gera um importante passivo ambiental. Portanto a utilização desse tipo de resíduo, possibilita a redução desse impacto ambiental.

Palavras-chave: Cinza de aterro sanitário. Concreto. Resistência à compressão.

\section{ABSTRACT}

The objective of this work is to identify the behavior of some traces of concrete in which there is the partial replacement of the natural sand by the landfill ash. Four traces were proposed, the first one with $100 \%$ natural sand, which will be used as reference traces, the second with 5\% ash from the landfill, in relation to the natural sand mass, the third with $10 \%$ ash, the room with $15 \%$ ash. The traces of the concretes were composed of cement, sand / ash, gravel and water, and these were tested for their compressive strength. The results showed that the composite traces with ash showed good performance with respect to the compressive strength. The relevance of this study is due to the fact that landfills, when used the process of burning the garbage, produce ashes, causing an impact on nature that generates an important environmental liability. Therefore, the use of this type of waste makes it possible to reduce this environmental impact.

Keywords: Landfill ash. Concrete. Compressive strength.

\section{INTRODUÇÃO}

Para Belive e Baccini [1], aterro de resíduos sólidos urbanos é uma instalação de tratamento, tendo por objetivo transformar o resíduo sólido em um resíduo de qualidade final que não afeta negativamente ao meio ambiente.

Segundo Itô [2], no Brasil existem três tipos de destinação dos resíduos, que podem ser os aterros sanitários, aterros controlados e lixões. Os lixões por possuir um sistema de disposição a céu aberto, contem grande risco de contaminação aos lençóis freáticos. Os aterros controlados possuem problemas parecidos com os lixões e são cobertos com terra. 
No ano de 2016 a quantidade de resíduos coletados no Brasil chegou a 71,3 milhões de toneladas. As Figuras 1 e 2 apresentam, em porcentagem, a disposição final dos resíduos sólidos urbanos no Brasil [3].

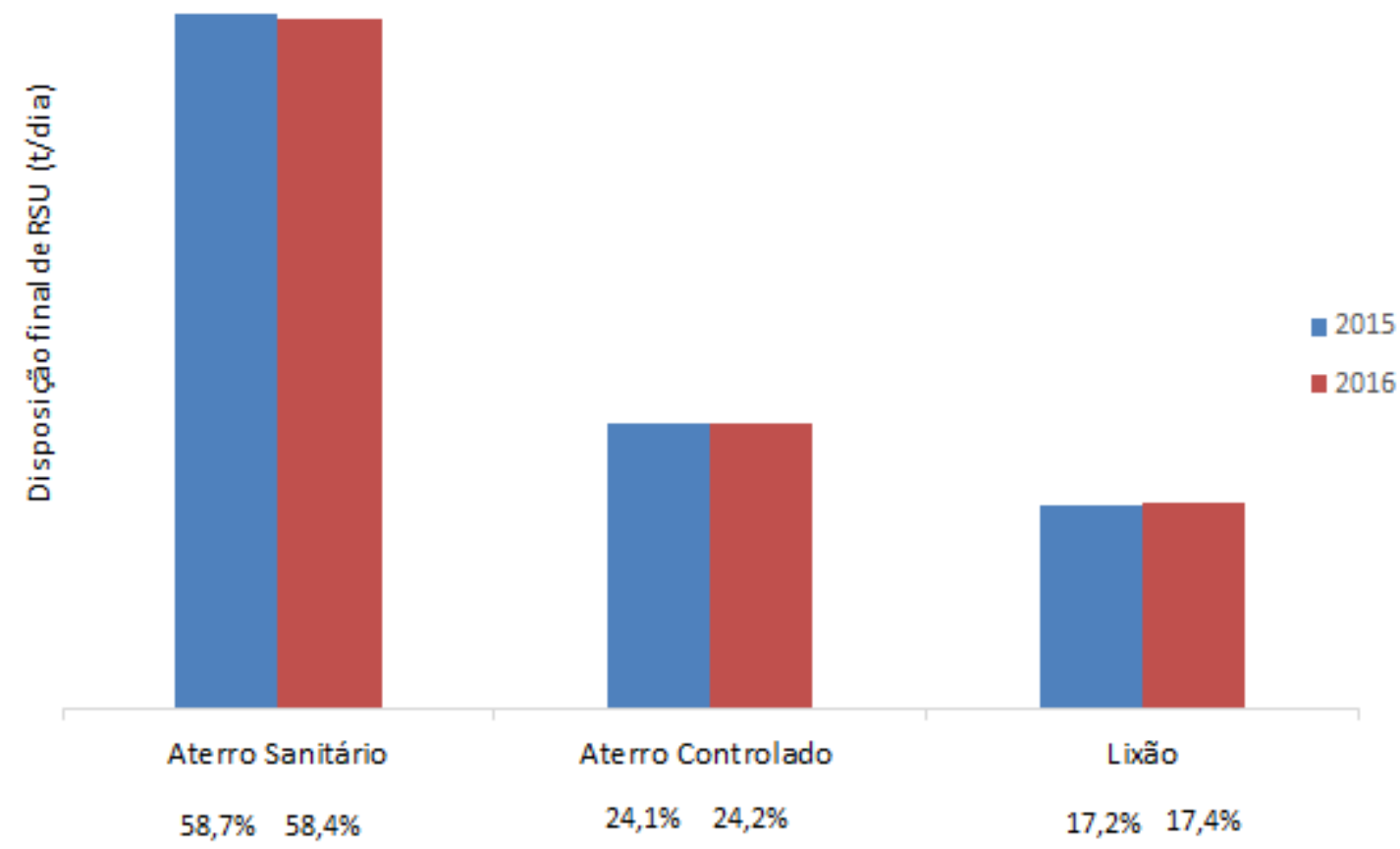

Figura 1: Disposição final dos resíduos sólidos urbanos coletados no Brasil (T/ano)

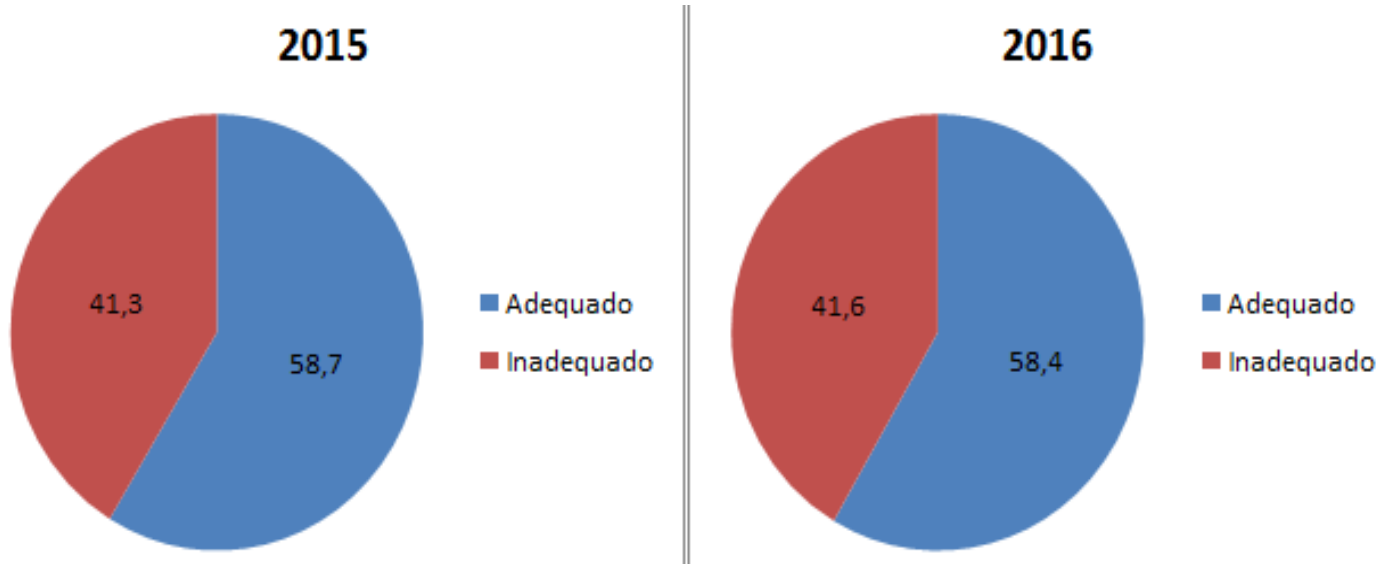

Figura 2: Comparativo da disposição final do resíduo sólido urbano (\%)

Segundo dados do Panorama dos Resíduos Sólidos no Brasil [3], em relação à disposição final dos resíduos no ano de 2016, houve uma piora quando comparado ao ano de 2015: cerca de 41,7 milhões de toneladas de resíduos sólidos urbanos foram destinados a aterros sanitários. Em relação a isso registrou-se um aumento no volume de resíduos que foram depositados em situação inadequada, cerca de 29,7 milhões de toneladas foram para lixões ou aterros controlados, locais que não possuem qualquer medida de proteção.

Os aterros sanitários de resíduos sólidos municipais representam, frequentemente, um problema ambiental devido à sua proximidade com áreas habitadas. Os riscos de poluição do solo para os ecossistemas nas áreas próximas estão especialmente ligados aos efeitos de poluição dos aterros de lixo sólido (industriais e urbanos). Dentre os diversos impactos que os resíduos sólidos podem causar no meio ambiente, estes se estendem também para a população, através da contaminação dos corpos d'água e dos lençóis freáticos, de forma direta ou indireta, e, as novas interações ocorridas no sistema devido, principalmente, à salinidade, toxicidade de metais pesados e contaminantes orgânicos [4] [5].

Devido ao potencial lixiviação de contaminantes, os aterros de resíduos, podem ter consequências a longo prazo para o meio ambiente. As soluções de disposição escolhidas para esses resíduos devem, portanto, 
ser sustentáveis em termos de impacto ambiental e consumo de energia [6].

Lino e Ismail [7] afirmam que nos países da Europa, Ásia e América, o cenário de tratamento do lixo mudou de terra para compostagem, reciclagem e incineração. Como apresenta a Tabela 1 [8] [9] [10] [11] [12] [13] [14] [15].

Tabela 1: Tratamento dos Resíduos Sólidos Municipais em alguns países

\begin{tabular}{|c|c|c|c|c|c|c|}
\hline PAÍS & ANO & $\begin{array}{l}\text { POPULAÇÃO } \\
(\text { MILHÃO) }\end{array}$ & \begin{tabular}{|lr} 
RESÍDUOS & SÓ- \\
LIDOS & MUNI- \\
CIPAIS & (MI- \\
LHÕES DE & TO- \\
NELADAS & $/$ \\
ANO) &
\end{tabular} & $\begin{array}{l}\text { ATERRO } \\
(\%)\end{array}$ & $\begin{array}{l}\text { INCINERAÇÃO } \\
(\%)\end{array}$ & $\begin{array}{l}\text { RECICLAGEM E } \\
\text { COMPOSTAGEM } \\
(\%)\end{array}$ \\
\hline Áustria & 2013 & 8,5446 & 8,14 & 4 & 37 & 59 \\
\hline Dinamarca & 2013 & 5,6691 & 4,2 & 2 & 54 & 44 \\
\hline Alemanha & 2013 & 80,6885 & 47,7 & 0 & 35 & 65 \\
\hline Países Baixos & 2013 & 16,9249 & 9,8 & 1 & 49 & 50 \\
\hline Suécia & 2013 & 9,7794 & 4,36 & 1 & 50 & 49 \\
\hline Suíça & 2013 & 8,2986 & 5,56 & 0 & 49 & 51 \\
\hline Bélgica & 2013 & 11,2292 & 6,136 & 1 & 44 & 55 \\
\hline Romênia & 2013 & 19,5113 & 0,783 & 97 & 0 & 3 \\
\hline Japão & 2013 & 126.5735 & 45 & $1 \%$ & 80 & 19 \\
\hline China & 2014 & 1376.0489 & 158,05 & 60 & 30 & 10 \\
\hline EUA & 2014 & 321.7736 & 273,1 & 53 & 12 & 35 \\
\hline Brasil & 2014 & 204.4506 & 64,4 & 96,1 & 0 & 3,9 \\
\hline
\end{tabular}

Para Hjelmmar [6], a incineração e o aterro são elementos integrantes da gestão de resíduos em todo mundo. A incineração, muitas vezes, é escolhida devido à disponibilidade limitada ou acessibilidade de espaço para o aterro sanitário.

A incineração acontece quando se tem um excesso de oxigênio para completa oxidação. Nos resíduos sólidos urbanos é capaz de reduzir em até $90 \%$ do seu volume, e seu peso em até $75 \%$, e, permite a reutilização destes em outros empreendimentos. Como, por exemplo, em alguns países onde esta cinza é utilizada para a construção de estradas [16].

Dentre os benefícios da incineração de resíduos, destacam-se a redução do volume requerido para disposição em aterros; a recuperação de energia durante a combustão, que pode ser utilizada para a produção de eletricidade ou combinado calor e energia, além de evitar o processo de emissão de metano (um potente gás de efeito estufa), que poderia aumentar com a disposição de lixo em aterro [17].

Tabasová et al. [16] defendem que na incineração há três estágios do processo: secagem e desgaseificação, pirólise e gaseificação, e, oxidação. A solução tecnológica aplicada em uma usina de incineração pode ter muitas diferenças de acordo com o tipo de lixo a ser incinerado. Na atualidade existem instalações de incineração de última geração, destinados a incinerar resíduos sólidos urbanos e resíduos perigosos ou industriais.

Segundo Dovetail Partners [18], os novos incineradores oferecem uma combustão mais completa, que pode chegar a temperaturas de 1000 até $2000{ }^{\circ} \mathrm{C}$, podendo, assim, capturar o calor gerado e gerenciar as emissões.

Morgado e Ferreira [17] defendem que a incineração pode ser ambientalmente correta, desde que, constituídas de medidas de proteção ao meio e com equipamentos capacitados para garantir o controle de emissão de poluição.

Alguns regulamentos existentes, a falta de incentivos econômicos, questões de responsabilidade, práticas de separação de resíduos e incerteza quanto às propriedades funcionais dos resíduos, bem como incertezas quanto à avaliação da extensão dos impactos ambientais e riscos para a saúde do incinerador de resíduos sólidos, criam obstáculos à utilização deste resíduos. Tornando o aterro ou o armazenamento as opções do- 
minantes ou únicas de gerenciamento de resíduos em vários países [6].

Além disso, a incineração é criticada por afetar a reciclagem, mesmo sendo indicado o processo de separação antes de ser incinerado. Na incineração é muito importante a retirada de produtos químicos domésticos, os resíduos médicos e baterias. Esse procedimento é essencial para proteção das águas subterrâneas e para reduzir os riscos relacionados com a eliminação das cinzas [18].

A cinza resultante do processo de incineração, geralmente é composta por alumínio, bário, cloretos, fenol, sulfato, sódio e tensoativos. Com isso, pode ser utilizada em aplicações na construção civil para diversos fins. Desta maneira pode eliminar grande quantidade de resíduo gerado, não havendo a necessidade de depositar este material em aterros sanitários.

Silva [19], afirma que a cinza pode ser utilizada em diversas aplicações dentro da construção civil. Podendo ser utilizada como substituição parcial para a matéria-prima de cerâmicas, sendo estes os tijolos, telhas e vidro, e também em aplicações em aterros.

Siddique [20] cita algumas aplicações da cinza de resíduo sólido urbano:

-Cimento: devido ao fato de conter silicatos e alumínio-silicato;

-Concreto: as cinzas podem ser aplicadas como um substituto em uma porcentagem da composição do cimento, e como material complementar em traços de concreto;

- Cerâmica: esse é um setor da indústria que necessita muito dos recursos naturais, a utilização da cinza se torna uma alternativa viável para esse ramo.

-Vidro: o uso da cinza, nesse caso, se dá através do processo de vitrificação, que faz com que a cinza seja transformada em uma substância parecida com o vidro, isso acontece queimando a cinza em temperaturas acima dos $1300^{\circ} \mathrm{C}$.

-Pavimento rodoviário: a cinza pode ser utilizada na substituição da areia ou cimento na base e sub-base de rodovias. Esta aplicação está relacionada com problemas ambientais, pois está diretamente ligada com a contaminação do solo e das águas subterrâneas.

Em relação às propriedades da cinza, Siddique [20], defende que a cinza resultante dos resíduos sólidos urbanos pode conter muitos metais pesados e tóxicos, como o chumbo, cádmio e também compostos orgânicos. A cinza de resíduo urbano em comparação a agregados e a areia, é um material leve e sua qualidade depende muito da natureza do tipo de lixo.

Tendo por base o exposto acima, o objetivo desta pesquisa é analisar o efeito da adição de cinza de aterro sanitário em concretos, substituindo, de forma parcial, o agregado miúdo.

\section{MATERIAIS E MÉTODOS}

\subsection{Materiais}

Foi utilizada cinza de aterro sanitário (lixo urbano). proveniente da cidade de Mafra (Santa Catarina, Brasil). Esta se apresentava úmida e por isso passou por uma secagem em uma estufa com temperatura controlada em aproximadamente $105^{\circ} \mathrm{C}$ e foi resfriada à temperatura ambiente. A sua umidade final ficou em torno de $15 \%$. Por ser uma amostra que contém vários elementos que não foram incinerados totalmente, após sua secagem, esta foi classificada em uma peneira número 8 , para a retirada desses elementos e, após essa preparação esta foi utilizada como substituição parcial do agregado miúdo na composição dos traços. $\mathrm{O}$ agregado miúdo utilizado foi a areia média e o agregado graúdo utilizado foi a brita 0 . Tanto a cinza como os agregados miúdos e graúdos foram classificados segundo a sua distribuição granulométrica, com base na NBR NM 248 [21].

Além da distribuição granulométrica da cinza, foi realizada a análise química semi quantitativa por meio de espectroscopia por fluorescência de Raios X (FRX).

O aglomerante utilizado foi o Cimento Portland composto por filer CP II F - 32, este foi escolhido devido a sua disponibilidade na região. As características químicas, físicas e mecânicas deste são apresentadas na Tabela 2. 
Tabela 2: Características químicas, físicas e mecânicas do Cimento CP II F-32 segundo a NBR 11578 [22]

\begin{tabular}{|c|c|c|c|}
\hline \multicolumn{4}{|c|}{ EXIGÊNCIAS QUÍMICAS } \\
\hline \multicolumn{3}{|c|}{ Classe de resistência } & 32 \\
\hline \multicolumn{3}{|c|}{ Clínquer+sulfatos de cálcio (\%) } & 94-90 \\
\hline \multicolumn{3}{|c|}{ Material Carbonático $(\%)$} & $6-10$ \\
\hline \multicolumn{3}{|c|}{ Resíduo Insolúvel (RI) } & $\leq 2,5$ \\
\hline \multicolumn{3}{|c|}{ Perda ao Fogo (PF) } & $\leq 6,5$ \\
\hline \multicolumn{3}{|c|}{ Óxido de magnésio (MgO) } & $\leq 6,5$ \\
\hline \multicolumn{3}{|c|}{ Trióxido de enxofre $\left(\mathrm{SO}_{3}\right)$} & $\leq 4,0$ \\
\hline \multicolumn{3}{|c|}{ Anidrido carbônico $\left(\mathrm{CO}_{2}\right)$} & $\leq 5,0$ \\
\hline \multicolumn{4}{|c|}{ EXIGÊNCIAS FISICAS E MECÂNICAS } \\
\hline \multirow{2}{*}{ Finura } & & síduo na peneira $75 \mu \mathrm{m}(\%)$ & $\leq 12,0$ \\
\hline & & ea específica $\left(\mathrm{m}^{2} / \mathrm{kg}\right)$ & $\geq 260$ \\
\hline \multicolumn{3}{|c|}{ Tempo de início de pega $(\mathrm{h})$} & $\geq 1$ \\
\hline \multicolumn{3}{|c|}{ Expansabilidade a quente (mm) } & $\leq 5$ \\
\hline \multirow{3}{*}{\multicolumn{2}{|c|}{$\begin{array}{l}\text { Resistência } \\
\text { compressão } \\
(\mathrm{MPa})\end{array}$}} & 3 dias de idade & $\geq 10,0$ \\
\hline & & 7 dias de idade & $\geq 20,0$ \\
\hline & & 28 dias de idade & $\geq 32,0$ \\
\hline
\end{tabular}

\subsection{Dosagem dos traços}

A dosagem adotada foi 1:2:3 (TR) (cimento:areia:brita), com as medidas em massa, e com um fator água/cimento de 0,6, para uma provável resistência à compressão de 25,4 MPa após 28 dias. Essa dosagem foi escolhida por ser mais comumente utilizada em diversas etapas da elaboração de peças estruturais.

A próxima etapa seria a porcentagem de cinzas a serem incorporadas no agregado miúdo, neste caso, 5\% (T1), 10\% (T2) e 15\% (T3) de cinzas substituindo no agregado miúdo, em relação ao peso deste. A Tabela 3 apresenta os traços adotados.

Tabela 3: Traços dos concretos moldados com cinza de aterro sanitário

\begin{tabular}{l|l|l|l}
\hline TRAÇO & $\begin{array}{l}\text { RELAÇÃO CIMENTO: AREIA: BRI- } \\
\text { TA (Traços em massa) }\end{array}$ & $\begin{array}{l}\text { RELAÇÃO } \\
\text { ÁGUA:CIMENTO }\end{array}$ & CINZA (\%) \\
\hline T1 & $1: 1,95: 3$ & 0,6 & 5 \\
\hline T2 & $1: 1,90: 3$ & 0,6 & 10 \\
\hline T3 & $1: 1,85: 3$ & 0,6 & 15 \\
\hline TR & $1: 2: 3$ & 0,6 & - \\
\hline
\end{tabular}

Após a definição dos traços foi realizada o ensaio de abatimento, slump test, conforme a NBR NM 67 [23].

\subsection{Preparo das amostras}

A moldagem dos corpos de prova cilíndricos foi feita em moldes com dimensão de $100 \mathrm{~mm}$ de diâmetro por $200 \mathrm{~mm}$ de altura, conforme NBR 5738 [24]. Os corpos de prova foram moldados realizando o preenchimento em duas camadas e 15 golpes, visando o correto adensamento das camadas. Após $24 \mathrm{~h}$ da cura inicial, os corpos de prova foram imersos em um tanque com água até as datas previstas para a retificação e rompimento.

\subsection{Ensaio mecânico}

O ensaio de resistência à compressão foi realizado em uma máquina universal de ensaios. Para cada amostra, os corpos de prova foram ensaiados aos 7, 14, 21 e 28 dias de idade. Os resultados foram analisados estatisti- 
camente, por meio de comparação múltipla entre médias pelo teste de Tukey com nível de confiança de $95 \%$.

\subsection{Difração de Raios X e microscopia eletrônica de varredura}

Para analisar a composição química dos corpos de prova com os diferentes teores de cinza, foi realizada a difração de Raios X (DRX). Utilizou-se o difratômetro de Raios X Shimadzu XRD-7000 (Shimatzu Co., modelo XRD-7000, operando a $30 \mathrm{kV}, 30 \mathrm{~mA}$ ). Os parâmetros de ensaio foram: ângulo de $5^{\circ}$ a $70^{\circ}$, passo de $0,02^{\circ}$ e velocidade de varredura de $2 \%$ min. A análise dos resultados foi realizada com auxílio do software X'Pert Highscore Plus com um banco de dados cristalográfico do ICDD (International Centre for Diffraction Data) de 2003.

\section{RESULTADOS E DISCUSSÕES}

\subsection{Materiais}

A curva de distribuição granulométrica do agregado graúdo utilizado é apresentada na Figura 3.

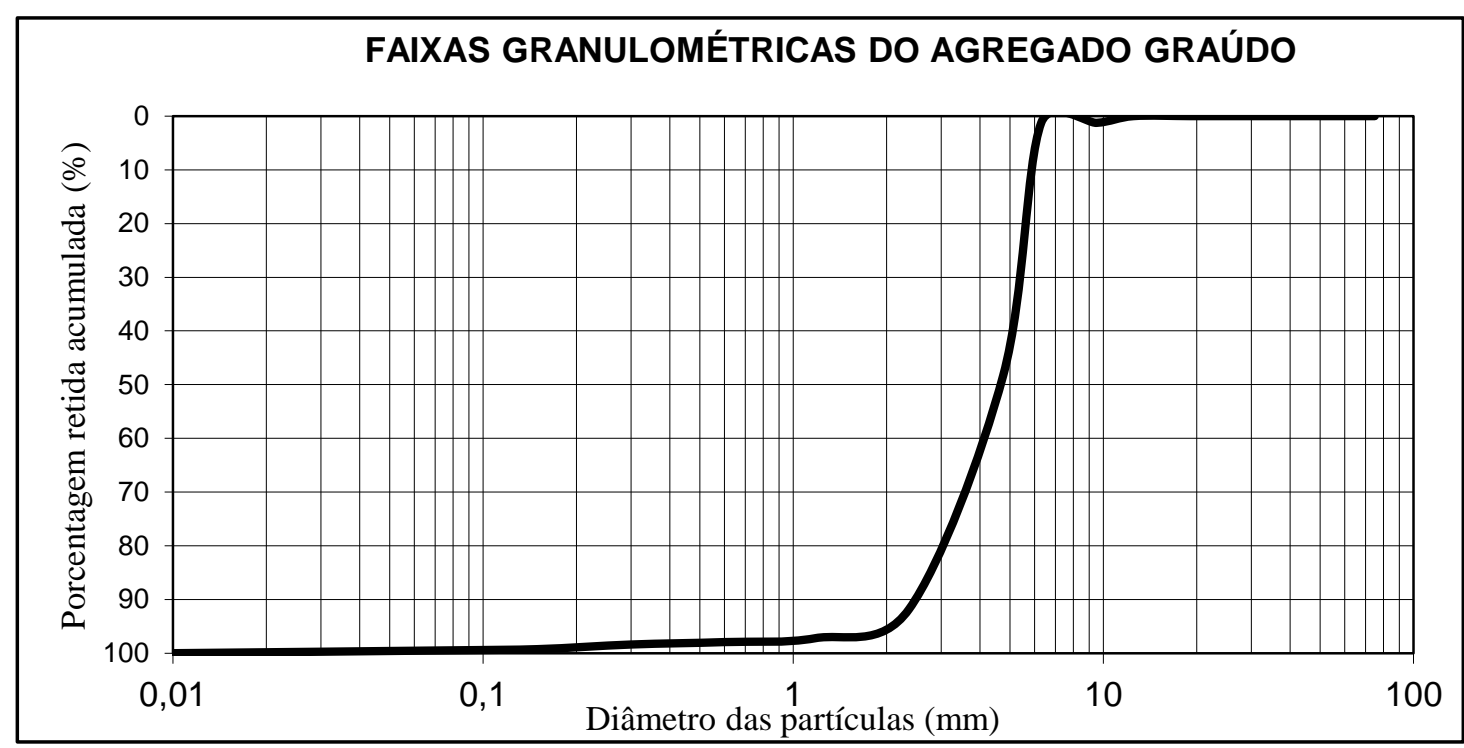

Figura 3: Distribuição granulométrica do agregado graúdo

$\mathrm{O}$ agregado graúdo pode ser classificado com brita 0 .

A curva granulométrica do agregado miúdo e da cinza do aterro sanitário são apresentadas na Figura 4.

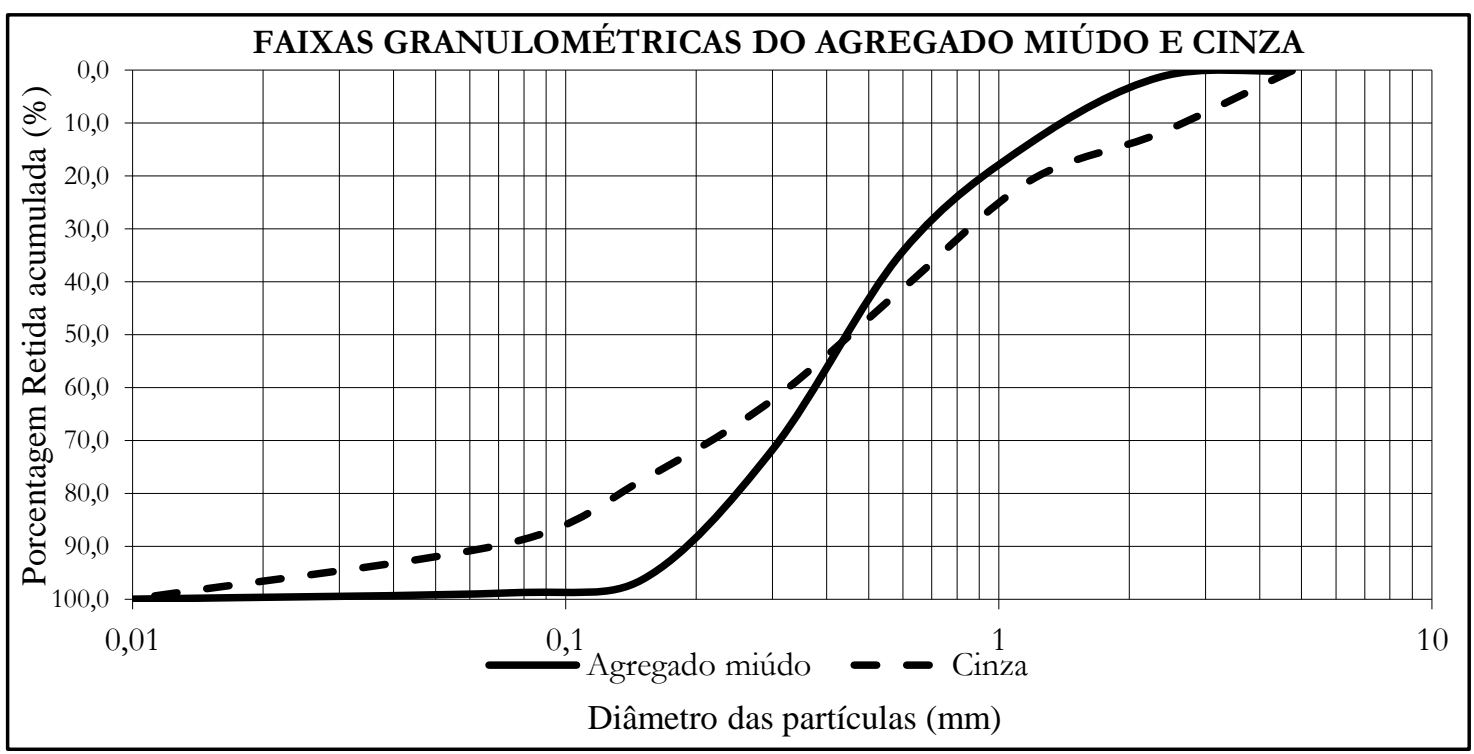

Figura 4: Distribuição granulométrica do agregado miúdo e da cinza 
O agregado miúdo utilizado foi a areia média, esta apresenta um módulo de finura de 2,17 e uma dimensão máxima característica de 2,17 e 2,36, respectivamente. Já cinza utilizada apresentou um módulo de finura de 2,75 e uma máxima dimensão característica de 2,36, demonstrando assim que há compatibilidade entre as granulometrias.

A Tabela 4 apresenta a análise química semi-quantitativa por espectroscopia por fluorescência de raios $\mathrm{X}$ da cinza.

Tabela 4: Composição química da cinza de aterro sanitário

\begin{tabular}{l|l}
\hline $\mathrm{COMPONENTE}$ & TEOR $(\%)$ \\
\hline $\mathrm{SiO}_{2}$ & 35,3 \\
\hline $\mathrm{CaO}$ & 16,2 \\
\hline $\mathrm{Al}_{2} \mathrm{O}_{3}$ & 9,5 \\
\hline $\mathrm{Fe}_{2} \mathrm{O}_{3}$ & 6,0 \\
\hline $\mathrm{MgO}$ & 3,7 \\
\hline $\mathrm{P}_{2} \mathrm{O}_{5}$ & 2,6 \\
\hline $\mathrm{Na}_{2} \mathrm{O}$ & 2,5 \\
\hline $\mathrm{K}_{2} \mathrm{O}$ & 1,5 \\
\hline $\mathrm{TiO}_{2}$ & 1,4 \\
\hline $\mathrm{Cl}$ & 1,1 \\
\hline $\mathrm{ZnO}$ & 1,0 \\
\hline $\mathrm{SO}$ & 0,7 \\
\hline $\mathrm{PbO}$ & 0,3 \\
\hline $\mathrm{CuO}$ & 0,3 \\
\hline $\mathrm{MnO}$ & 0,1 \\
\hline $\mathrm{Cr} \mathrm{O}_{3}$ & 0,1 \\
\hline $\mathrm{SrO}$ & 0,1 \\
\hline $\mathrm{Perda}$ ao Fogo & 17,62 \\
\hline
\end{tabular}

Verifica-se que esta apresenta um teor elevado de sílica $\left(\mathrm{SiO}_{2}\right)$ em sua composição, o que para uso em concreto é uma boa qualidade, devido ao fato de que a sílica pode reagir com o hidróxido de cálcio, presente no matriz cimentícia, e formar uma quantidade extra de gel C-S-H (silicato de cálcio hidratado), sendo este responsável pela resistência do cimento [25].

\subsection{Ensaio mecânico}

Os resultados obtidos com o ensaio de resistência à compressão dos corpos de prova são apresentados na Tabela 5.

Tabela 5: Resistência à compressão dos corpos de prova nas idades de 7, 14, 21 e 28 dias, fator a/c =0,6

\begin{tabular}{l|l|l|l|l}
\hline TRAÇO & \multicolumn{4}{l}{ RESISTÊNCIA À COMPRESS ÃO $(\mathrm{MPa})$} \\
\hline & 7 dias & 14 dias & 21 dias & 28 dias \\
\hline T1 & $15,32^{\mathrm{AB}}$ & $21,74^{\mathrm{AB}}$ & $24,98^{\mathrm{A}}$ & $25,90^{\mathrm{B}}$ \\
\hline $\mathrm{T} 2$ & $13,23^{\mathrm{BC}}$ & $17,81^{\mathrm{BC}}$ & $21,00^{\mathrm{BC}}$ & $22,23^{\mathrm{C}}$ \\
\hline $\mathrm{T} 3$ & $11,31^{\mathrm{C}}$ & $15,47^{\mathrm{C}}$ & $17,14^{\mathrm{C}}$ & $18,65^{\mathrm{D}}$ \\
\hline TR & $16,55^{\mathrm{A}}$ & $24,02^{\mathrm{A}}$ & $29,35^{\mathrm{A}}$ & $32,67^{\mathrm{A}}$ \\
\hline $\begin{array}{l}\text { *Médias seguidas pela mesma letra dentro da mesma coluna não se diferenciam estatisticamente, a 5\% de } \\
\text { probabilidade, pelo teste de Tukey. }\end{array}$
\end{tabular}

Verifica-se que a resistência à compressão dos compósitos vai aumentando nas diferentes idades de 
rompimento. Ainda, verifica-se que o traço com substituição de 5\% da areia média pela cinza foi o traço com maior resistência. Pelo teste de Tukey, pôde-se afirmar que há diferença significativa para as médias da resistência à compressão dos corpos de prova.

Este aumento da resistência à compressão dos corpos de prova ocorre devido ao fato de que a cinza apresenta um alto teor de sílica em sua composição, esta quando em contato com a matriz cimentícia reage com o hidróxido de cálcio presente na pasta, formando uma quantidade extra de silicato de cálcio hidratado, sendo este o principal responsável pelo aumento da resistência à compressão da matriz cimentícia.

\subsection{Difração de Raios X}

Nas figuras 5, 6, 7 e 8 são apresentados os difratogramas de Raios X na idade de 28 dias, dos traços de concreto moldados, e a legenda para os picos dos difratogramas.

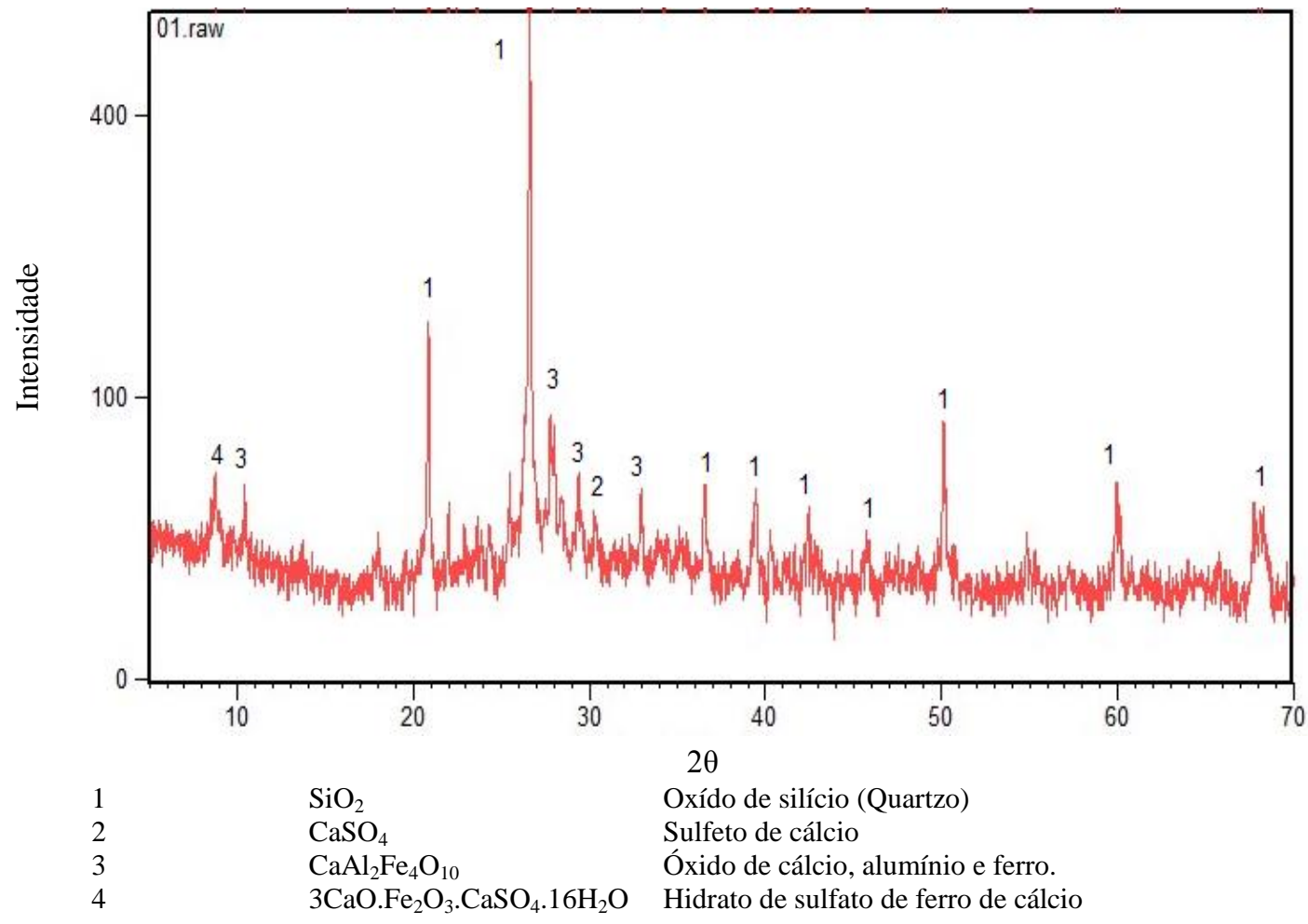

Figura 5: Difratograma de Raios $X$ do traço referência

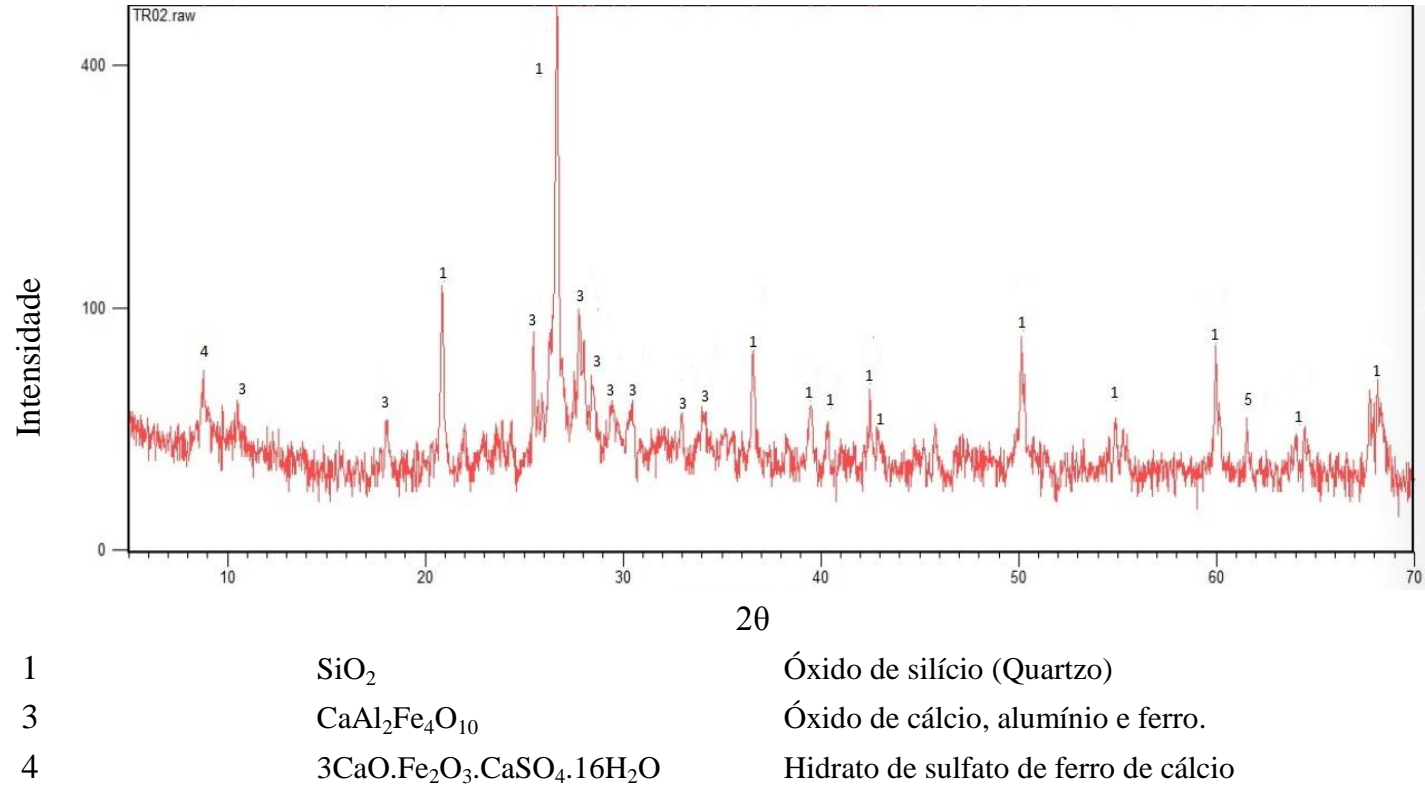


Figura 6: Difratograma de Raios X do traço com 5\% de substituição da areia natural pela cinza de aterro sanitário

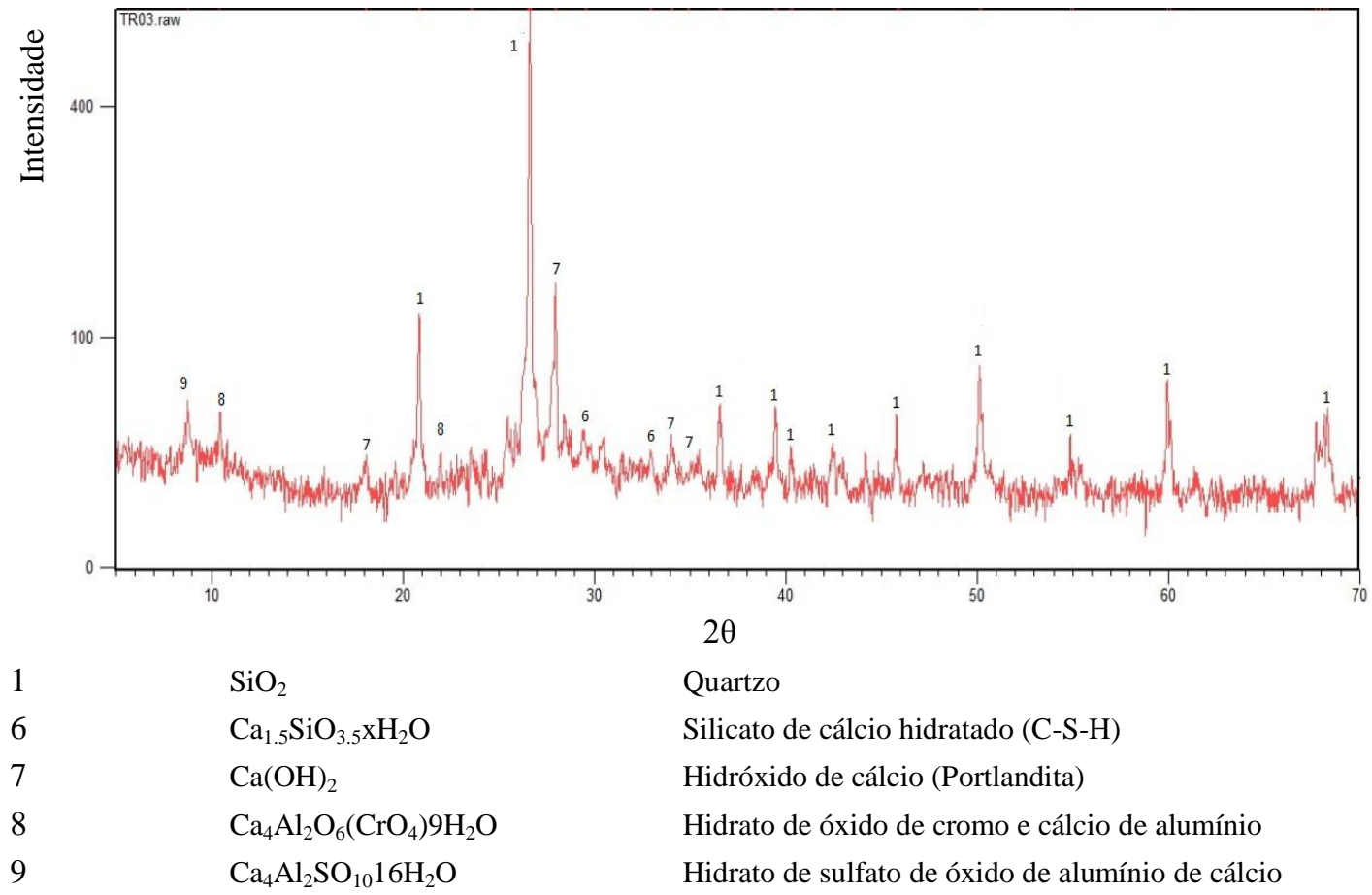

Figura 7: Difratograma de Raios X do traço com 10\% de substituição da areia natural pela cinza de aterro sanitário

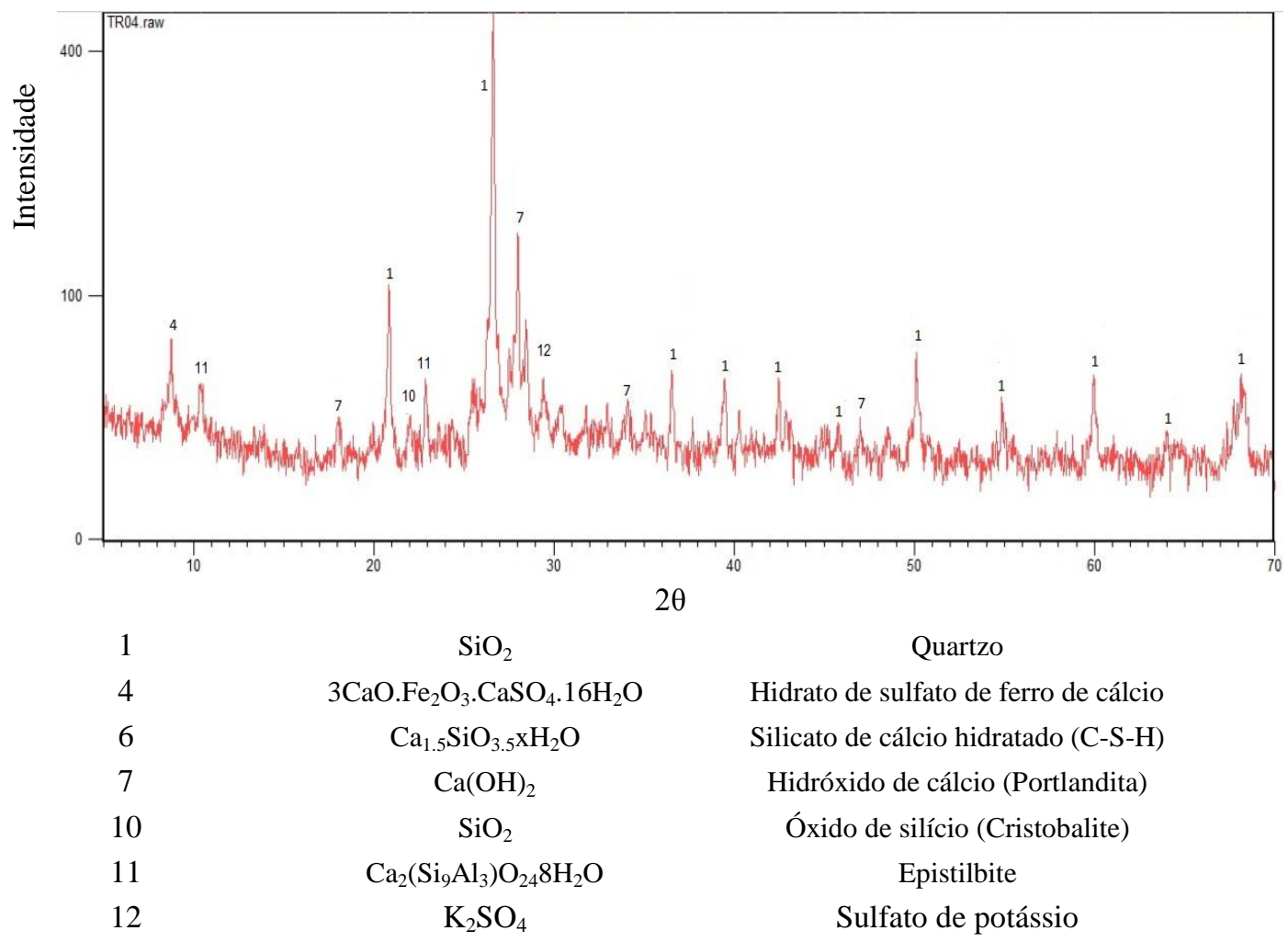

Figura 8: Difratograma de Raios X do traço com 15\% de substituição da areia natural pela cinza de aterro sanitário

Observa-se em todos os difratogramas que o principal mineral é o quartzo $\left(\mathrm{SiO}_{2}\right)$, verifica-se ainda, 
que quase todos os picos de DRX de quartzo possuem duplicações, estas surgem devido ao processo de destruição mecânica (fissuras, abrasões, etc) das partículas de areia. Após a dissolução destas camadas destruídas do grão de areia em ambiente altamente alcalino (pH próximo a 13), as intensidades dos picos de quartzo aumentam, uma vez que as superfícies do mineral foram expostas. [26]

$\mathrm{O} \mathrm{SiO}_{2}$ amorfo dissolvido reage com o hidróxido de cálcio $(\mathrm{CaO})$ livre presente no cimento, este $\mathrm{SiO}_{2}$ amorfo pode precipitar, como por exemplo, na síntese do gel de tobermita ou como o silicato de cálcio hidratado (C-S-H), este torna-se um aglutinanete entre as partículas sólidas do material. O crescimento de substâncias cristalinas e amorfas de carbonatos e formação de CSH pode ser responsável pelo ganho nas propriedades mecânicas dos materiais. [26] [27]

\section{CONCLUSÕES}

Verifica-se que a cinza de aterro sanitário apresenta granulometria para ser utilizada como substituição do agregado miúdo. Em sua composição química esta apresenta um alto teor de sílica $\left(\mathrm{SiO}_{2}\right)$, que em contato com o hidróxido de cálcio presente na matriz cimentícia reage formando uma quantidade extra de silicato de cálcio hidratado, responsável pelo aumento da resistência do cimento.

Para a resistência à compressão, o teor de $5 \%$ de cinza, como substituição do agregado miúdo, apresentou os valores mais elevados, apresentando até os 21 dias valores próximos do traço referência, demonstrando assim, que a adição da cinza auxiliou no aumento da resistência nas idades iniciais.

Conclui-se que a cinza de aterro sanitário pode ser utilizada para a substituição parcial da areia natural, resultando em uma melhora da resistência à compressão do concreto.

\section{BIBLIOGRAFIA}

[1] BELEVI, H., BACCINI, P. "Long-term behavior of municipal solid waste landfills", Waste Management \& Research, v. 7, n. 1, p. 43-56, 1989.

[2] ITÔ, L. C. M. "Geração de Energia Elétrica a partir de Resíduos Sólidos Urbanos”. São Carlos, 2014. Trabalho de Conclusão de Curso - Escola de Engenharia de São Carlos da Universidade de São Paulo, São Carlos, 2014.

[3] ABRELPE. Panorama dos Resíduos Sólidos no Brasil 2016. São Paulo, ABRELPE 2016.

[4] PASTOR, J., HERNANDEZ, A. J. "Heavy metals, salts and organic residues in old solid urban waste landfills and surface waters in their discharge areas: Determinants for restoring their impact", Journal of environmental management, v. 95, p. S42-S49, 2012.

[5] FERREIRA, J. A., ANJOS, L. A. "Aspectos de saúde coletiva e ocupacional associados à gestão dos resíduos sólidos municipais”, Cad. Saúde Pública. v. 17, n. 3, pp. 689-696, 2001.

[6] HJELMAR, OLE. "Disposal strategies for municipal solid waste incineration residues", Journal of hazardous materials, v. 47, n. 1-3, p. 345-368, 1996.

[7] LINO, F. A. M., ISMAIL, K. A. R. "Incineration and recycling for MSW treatment: Case study of Campinas, Brazil”, Sustainable Cities and Society, v. 35, pp. 752-757, 2017.

[8] Eurostat. Sustainable development in the European Union: Monitoring report of the EU sustainable development strategy. Luxemburg: Eurostat Statistical books. http://www.ec.europa.eu/eurostat/documents/3217494/6975281/KS-GT-15-001-EN-N, 2015.

[9] OECD. Environment at a glance 2015: OECD indicators. Paris, OECD Publishing, 2015.

[10] US EPA. Advancing sustainable materials management: 2013 fact sheet, assessing trends in material generation, recycling and disposal in the United States. Environmental Protection Agency, 22 p, 2015.

[11] BRASIL/SNIS. Diagnóstico do Manejo de Resíduos Sólidos Urbanos 2014. Brasília, BR: Sistema Nacional de Informações sobre Saneamento, SNIS, Ministério das Cidades. http://www.mma.gov.br/snis. 2016.

[12] EEA. Managing municipal solid waste: A review of achievements in 32 European countriesEuropean Environment Agency EEA report n. 2. 2013.

[13] IBGE. Cidade-população de Campinas em 2015. Fundação Instituto Brasileiro de Geografia e Estatística http://www.ibge.gov.br/cidade/populacao, 2016.

[14] IBGE. Banco de dados, Países: População em 2015. Fundação Instituto Brasileiro de Geografia e Esta- 
tística http://www.ibge.gov.br/paisesat/main_frameset. 2016.

[15] MOE. Ministry of the Environment, History and Current State of Waste Management in Japan. https://www.env.go.jp/en/recycle/smcs/attach/hcswm.pdf. 2014.

[16] TABASOVÁ, A. "Waste-to-energy technologies: Impact on environment", Energy. v. 44, n. 1, p. 146$155,2012$.

[17] MORGADO, T. C., FERREIRA, O. M. "Incineração de Resíduos Sólidos Urbanos, Aproveitamento na Co-geração de Energia. Estudo para a Região Metropolitana de Goiânia”, 2012.

[18] DOVETAIL PARTNERS, I. "Plasma gasification: An examination of health, safety, and environmental records of established facilities" City of Palisade, EUA, DOVETAIL PARTNERS. 2010.

[19] SILVA, R. V. "Use of municipal solid waste incineration bottom ashes in alkali-activated materials, ceramics and granular applications: A review”, Waste Management. v. 68, pp. 207-220, 2017.

[20] SIDDIQUE, RAFAT. "Use of municipal solid waste ash in concrete", Resources, Conservation and Recycling, v. 55, n. 2, pp. 83-91, 2010.

[21] ASSOCIAÇÃO BRASILEIRA DE NORMAS TÉCNICAS. NBR NM 248: - Agregados - Determinação da composição granulométrica. Rio de Janeiro. 6 p, 2003.

[22] ASSOCIAÇÃO BRASILEIRA DE NORMAS TÉCNICAS. NBR 11578: - Cimento Portland Composto. Rio de Janeiro. 5 p, 1991.

[23] ASSOCIAÇÃO BRASILEIRA DE NORMAS TÉCNICAS. NBR NM 67: - Concreto - Determinação da consistência pelo abatimento do tronco de cone. Rio de Janeiro. 8 p, 1998.

[24] ASSOCIAÇÃO BRASILEIRA DE NORMAS TÉCNICAS. NBR 5738: - Concreto - Procedimento para moldagem e cura de corpos-de-prova. Rio de Janeiro. 6 p, 2003.

[25] BIRICK, H., AKOZ, F., BERKTAY, I., et al., "Study of pozzolanic properties of wheat straw ash", $C e$ ment and Concrete Research, v. 29, pp. 637 - 643, 1999.

[26] MYMRIN, V. A. "Empleo de residuos industriales siderúrgicos como materiales aglomerantes en construcción”, Revista de Metalurgia, v. 34, n. Extra, pp. 441-447, 1998.

[27] MYMRIN, V., STELLA, J. C., SCREMIM, C. B., et al., "Utilization of sediments dredged from marine ports as a principal component of composite material", Journal of Cleaner Production, v. 142, pp. 4041-4049, 2017.

ORCID

Luana Cechin

Marcio Leandro Consul de Oliveira

Mariane Arruda Martins

Olaf Graupmann https://orcid.org/0000-0002-3735-1889

https://orcid.org/0000-0003-4257-6334

Sem ORCID

https://orcid.org/0000-0003-2227-1437 